\title{
SYNGAP1 Links the Maturation Rate of Excitatory Synapses to the Duration of Critical-Period Synaptic Plasticity
}

\author{
James P. Clement, ${ }^{1}$ Emin D. Ozkan, ${ }^{1}$ Massimiliano Aceti, ${ }^{1}$ Courtney A. Miller, ${ }^{1,2}$ and Gavin Rumbaugh ${ }^{1}$ \\ Departments of ${ }^{1}$ Neuroscience and ${ }^{2}$ Metabolism and Aging, The Scripps Research Institute, Jupiter, Florida 33458
}

Critical periods of developmental plasticity contribute to the refinement of neural connections that broadly shape brain development. These windows of plasticity are thought to be important for the maturation of perception, language, and cognition. Synaptic properties in cortical regions that underlie critical periods influence the onset and duration of windows, although it remains unclear how mechanisms that shape synapse development alter critical-period properties. In this study, we demonstrate that inactivation of a single copy of syngap1, which causes a surprisingly common form of sporadic, non-syndromic intellectual disability with autism in humans, induced widespread early functional maturation of excitatory connections in the mouse neocortex. This accelerated functional maturation was observed across distinct areas and layers of neocortex and directly influenced the duration of a critical-period synaptic plasticity associated with experience-dependent refinement of cortical maps. These studies support the idea that genetic control over synapse maturation influences the duration of critical-period plasticity windows. These data also suggest that critical-period duration links synapse maturation rates to the development of intellectual ability.

\section{Introduction}

Developmental critical periods refer to heightened levels of neural plasticity that enable use-dependent reorganization of brain circuits (Hensch, 2004). Critical windows of development exist for sensory systems, social skills, and intellectual ability (Hensch, 2004; Fox and Wong, 2005). The reorganization of neuronal circuits during critical periods is facilitated, at least in part, by heightened periods of synaptic plasticity that emerge at particular times during brain development (Feldman et al., 1999; Yashiro and Philpot, 2008). Taking into consideration the fundamental role that synaptic plasticity plays in neural development, combined with the high bias of disease-causing mutations that target synapse function (Grant, 2012), it is likely that some of these mutations do so by fundamentally altering critical-period efficacy (LeBlanc and Fagiolini, 2011). Thus, studying these mutations in developmental settings will inform our understanding of the etiology of neurodevelopmental disorders while at the same time providing insight into how synaptic properties influence normal developmental processes that shape the maturing nervous system.

We recently reported (Clement et al., 2012) that syngap1 heterozygous knock-out (Het) mice, which model a surprisingly common form of monogenic, non-inherited intellectual disabil-

Received Feb. 19, 2013; revised April 22, 2013; accepted May 16, 2013.

Author contributions: J.P.C., E.D.O., M.A., C.A.M., and G.R. designed research; J.P.C., E.D.O., and M.A. performed research; J.P.C., E.D.O., and G.R. analyzed data; G.R. wrote the paper.

This work was supported by National Institute for Neurological Disorders and Stroke Grant R01NS064079 (G.R.), National Institute for Mental Health Grant R01MH096847 (G.R.), and National Institute for Drug Abuse Grants R01 DA034116 and R03 DA033499 (C.A.M.). We thank Dr. Damon Page at The Scripps Research Institute for comments related to a previous version of this manuscript.

Correspondence should be addressed to Gavin Rumbaugh, Department of Neuroscience, The Scripps Research Institute (Scripps Florida), \#3C2, Jupiter, FL 33458. E-mail: grumbaug@scripps.edu.

DOI:10.1523/JNEUROSCI.0765-13.2013

Copyright $\odot 2013$ the authors $\quad 0270-6474 / 13 / 3310447-06 \$ 15.00 / 0$ ity with comorbid autism and epilepsy in humans (Hamdan et al., 2009, 2011; Pinto et al., 2010; Berryer et al., 2013), promote the early maturation of hippocampal dendritic spine synapses. This early synapse maturation triggers a defined form of neonatal hippocampal excitatory/inhibitory (E/I) imbalance that promotes seizures and behavioral dysfunction. syngap1 encodes a synaptic RasGAP (SynGAP) that is primarily localized to excitatory synapses in neocortical pyramidal neurons in which it potently regulates glutamate receptor trafficking and synaptic efficacy (Kim et al., 1998; Rumbaugh et al., 2006). Depending on the isoform expressed, SynGAP can either augment or decrease synaptic strength (Rumbaugh et al., 2006; McMahon et al., 2012). However, we recently reported that the net effect of syngap1 haploinsufficiency during development was to unleash dendritic spine synapse development in the neonatal hippocampus, which then drives E/I imbalance, behavioral alterations, and seizures (Clement et al., 2012). Interestingly, syngap1 mutations induced in adulthood had minimal impact on synaptic function, indicating a critical period for this gene specifically in neural development, although it is unknown whether syngap1 regulates synapse maturation rates in areas outside the hippocampus. Together, studying these truncating syngap1 mutations in the context of brain development is an attractive platform for understanding how alterations in synaptic maturation rates affect the emergence of balanced excitability, sociability, and cognition. Additionally, because the developmental role of SynGAP is to repress excitatory synapse maturation that shapes cognition, this model offers a unique system to directly test the hypothesis that synapse maturation rates link properties of critical-period plasticity to the development of cognitive and social ability.

\section{Materials and Methods}

Acute slice preparation. All experimental animals were bred and maintained in the Animal Resource Centre at The Scripps Research Institute. 
A
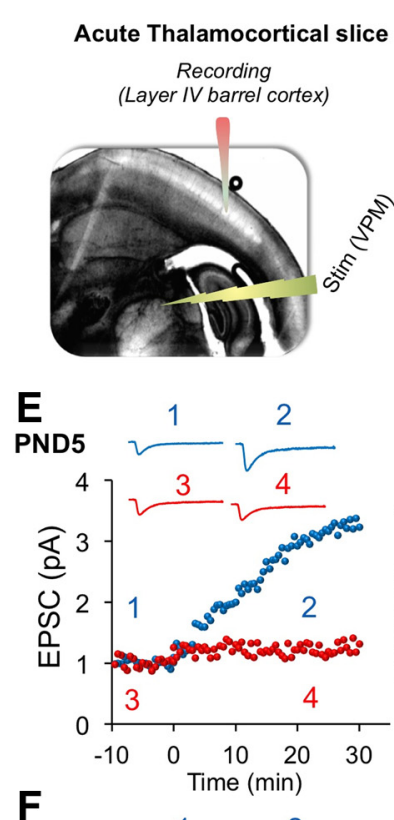

B
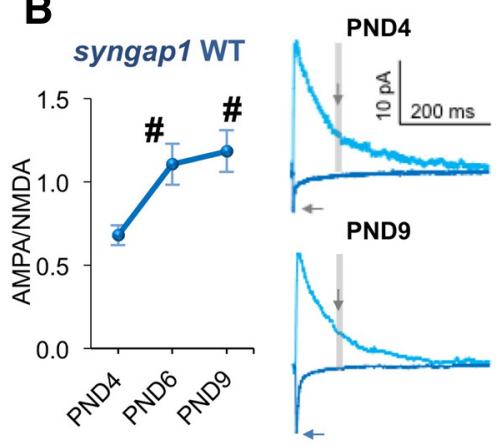

C
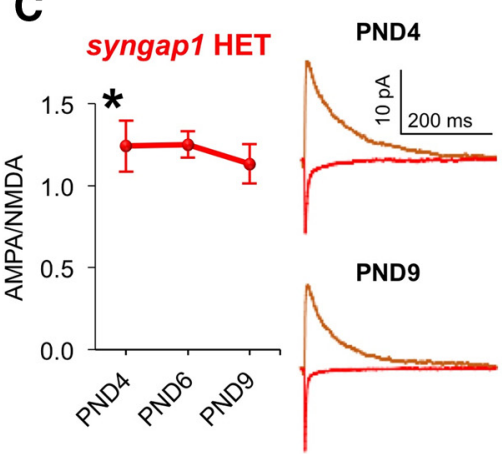

D

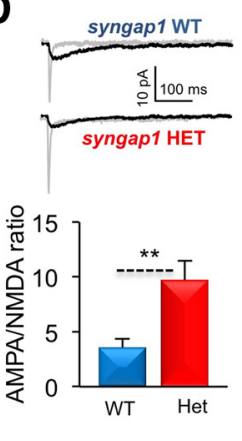

G
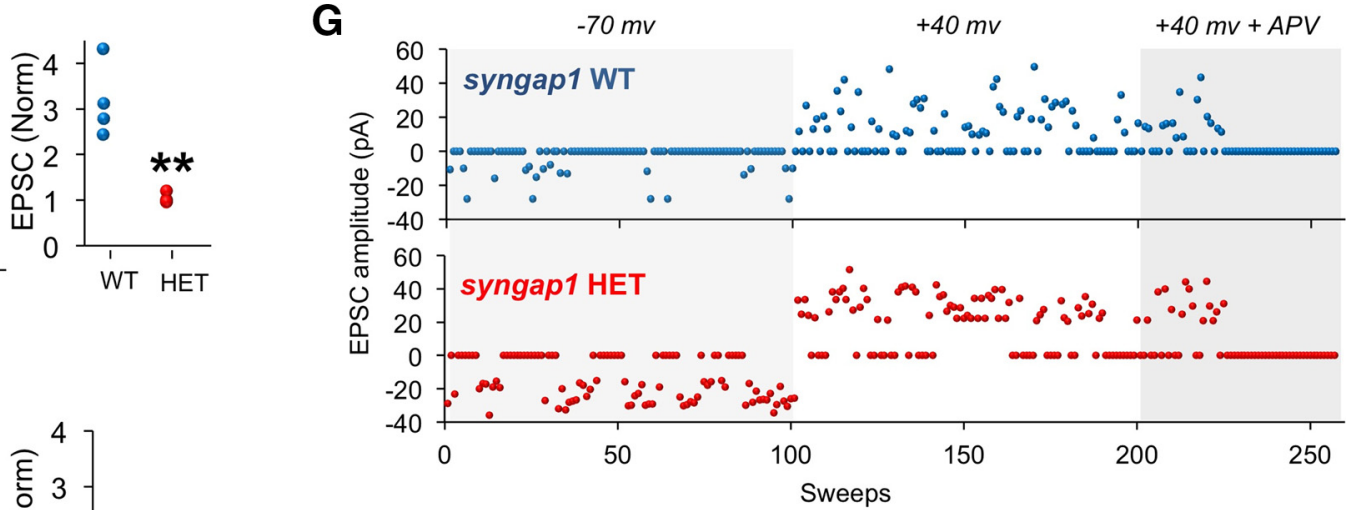
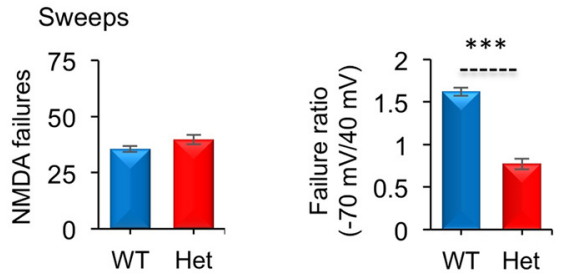

Figure 1. syngap 1 inactivation induces early maturation of TC synapses through a precocious accumulation of synaptic AMAPRs that directly restricts the duration of a critical-period plasticity window. A, Low-magnification image of TC fixed WT P9 slice showing the placement of stimulating electrode and recording electrode. $\boldsymbol{B}$, Representative traces and summary data of A/N ratios evoked in VPM and patch clamp recorded in layer IV WT stellate cells at P4 $(n=6), \mathrm{P} 6(n=8)$, and P9 $(n=6)$. C, Same as $\boldsymbol{B}$ but in Het P4 [P4 $(n=6), \mathrm{P} 6(n=7)$, and P9 $(n=8)]$. ** $p<0.01$ between genotypes; ${ }^{*} p<0.01$ within genotypes (2-way ANOVA; Bonferroni's pairwise comparison). Arrows and dark gray bars indicate the time point at which measurement was obtained from all the experiments. D, Sequential measurement of isolated AMPAR-mediated (gray) and NMDAR-mediated (black) currents from neurons recorded in P5 TC slices (WT, $n=10$; Het, $n=6$ ). ${ }^{* *} p<$ 0.01 , Student's $t$ test. The A/N ratio was calculated for each cell by measuring the peak of each component at $-70 \mathrm{mV}$. E, Representative recording and summary population data of $L T P s$ evoked in VPM and perforated patch clamp recorded in layer IV stellate cells in P5 WT $(n=4)$ and Het $(n=4)$ animals. ${ }^{* *} p<0.01$, repeated-measures ANOVA. F, Same as $\boldsymbol{E}$ but in P8 (WT, $n=4$; Het, $n=$ 5). G, Top, An example recording of a minimal stimulation protocol designed to uncover silent synapses in TC slices derived from WT or Het mice at P5. Bottom, Summary of population data demonstrating a reduction in the number of silent synapses in P5 Het animals (WT, $n=4$; Het $=n=4$ ). ${ }^{* * *} p<0.001$, Student's $t$ test. PND, Postnatal day.

The generation of syngap1 conventional Het mice have been described previously (Kim et al., 2003; Guo et al., 2009). Mice of both sexes were killed by cervical dislocation in accordance with the National Institutes of Health Guide for the Care and Use of Laboratory Animals and protocols approved by the Scripps Institutional Animal Care and Use Committee. For slice physiology studies, tissue was prepared as described previously (Clement et al., 2012). All measurements were performed by an experimenter blind to the experimental conditions. Using these general methods, we prepared two different acute slice preparations: (1) acute medial prefrontal cortex (mPFC) slices $(350 \mu \mathrm{m})$ containing infralimbic, perilimbic, and cingulate cortex were prepared from postnatal day 3 (P3) to P9 animals; and (2) acute thalamocortical (TC) slices $(400 \mu \mathrm{m})$ prepared as described by Agmon and Connors (1991) from P4-P9 syngap1 wildtype (WT) and Het mice.

Electrophysiology. Whole-cell voltage-clamp experiments were made from visually identified spiny stellate cells in layer IV barrel cortex in TC slices or layer $2 / 3$ neurons in $\mathrm{mPFC}$ slices using borosilicate glass pipettes (7-10 $\mathrm{M} \Omega$; $0.6 \mathrm{~mm}$ inner diameter; $1.2 \mathrm{~mm}$ outer diameter; Harvard Apparatus) filled with the following internal solution (in $\mathrm{mM}$ ): 130 $\mathrm{CsMeSO}_{4}, 5 \mathrm{NaCl}, 10$ HEPES free acid, 0.2 EGTA, 0.3 GTP-Na salt, and 4 ATP-Mg salt, $\mathrm{pH}$ 7.3. In mPFC slices, we evoked EPSCs by placing a bipolar electrode in the cell layer $\sim 50 \mu \mathrm{m}$ from the recorded neuron. In the TC preparation, EPSCs were generated by placing a concentric bipolar stimulating electrode ( $25 \mu \mathrm{m}$ inner diameter; $125 \mu \mathrm{m}$ outer diameter; FHC) in the ventral posteromedial nucleus (VPM) of the thalamus. Only stable evoked EPSC recordings exhibiting a constant latency that did not change with increasing stimulation intensity or stimulation rate were accepted as monosynaptic TC inputs (Feldman et al., 1999). To further confirm that the patched cells were indeed spiny stellate cells, the internal solution was mixed with Alexa Fluor 594 (Invitrogen). Cells with resistance $>30 \mathrm{M} \Omega$ at any time of the experiment were discarded from the analysis. The stimulation pulse intensity and duration were regulated by a constant-current isolated stimulator unit (Digitimer). AMPA receptor (AMPAR)-mediated currents were evoked at $0.1 \mathrm{~Hz}$ by extracellular stimulation in VPM and measured by holding the cell at $-70 \mathrm{mV}$ in normal aCSF. NMDA receptor (NMDAR)-mediated currents were then acquired by holding the cell at $+40 \mathrm{mV}$ in the presence of $10 \mu \mathrm{m}$ bicuculline, and the peak was calculated by measuring the mean current over a $2.5 \mathrm{~ms}$ window, $70-80 \mathrm{~ms}$ after the onset of the outward current. The $\mathrm{A} / \mathrm{N}$ ratio was determined by calculating the peak of AMPAR currents and NMDAR currents. In GluN2B-to-GluN2A switchover experiments, $5 \mu \mathrm{M}$ 2,3-dihydroxy-6-nitro-7-sulfamoyl-benzo[f] quinoxaline-2,3- 
A

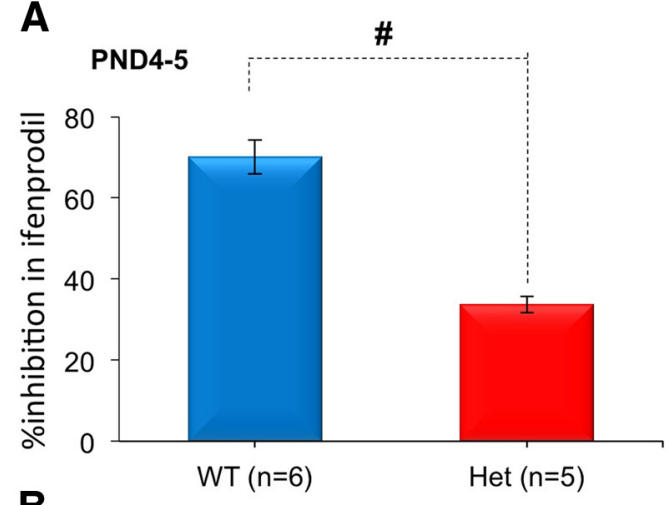

B

PND8-9

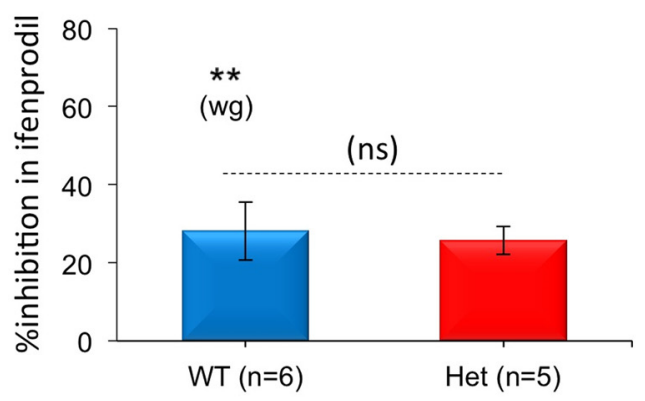

WT
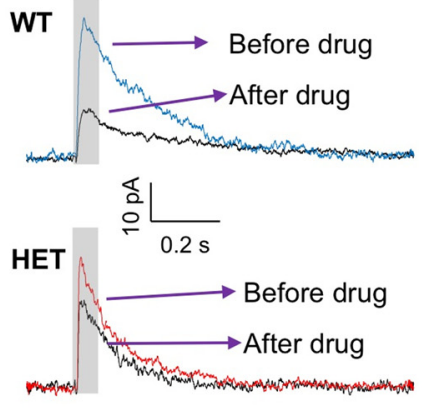

WT
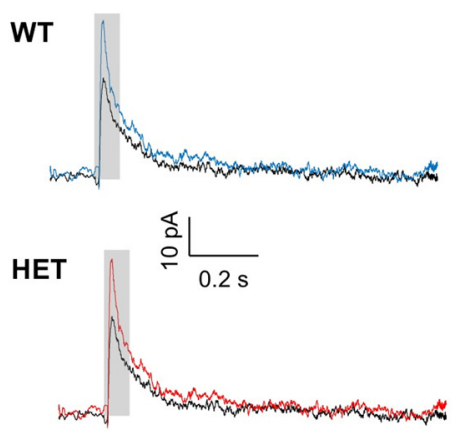

Figure 2. syngap1 mutations accelerate GluN2A incorporation into developing TC synapses. $\boldsymbol{A}$, Representative traces and summary data of GluN2B sensitivity to $3 \mu$ m ifenprodil recorded from layer IV stellate cells in P4-P5 WT and Het mice. B, Same as $A$ but in $\mathrm{P} 8-\mathrm{P9}$. ${ }^{* *} p<0.01$ within genotypes (wg) and ${ }^{\#} p<0.01$ between genotypes (2-way ANOVA, Bonferroni's pairwise comparison). Gray bar indicates the point at which measurement was obtained from all the cells. PND, Postnatal day.

\section{Results}

Creation of an acute slice preparation that leaves intact connections from the thalamus to layer IV of the barrel cortex (Fig. 1A) has facilitated the understanding of how synapses in this system mature and how experience contributes to reorganization of somatosensory circuits (Agmon and Connors, 1991). For instance, there is a gradual increase in the $\mathrm{A} / \mathrm{N}$ ratio at excitatory synapses from P3 to P7. Interestingly, the ability to induce LTP at this synapse is inversely related to the $\mathrm{A} / \mathrm{N}$ ratio (Crair and Malenka, 1995), which reflects the need to convert synapses from "silent" to "functional" to express LTP (Isaac et al., 1997). This conversion process requires insertion of AMPARs into synaptic locations, a process robustly regulated by SynGAP (Rumbaugh et al., 2006). Therefore, measuring developmental changes in the $\mathrm{A} / \mathrm{N}$ ratio at this synapse is an attractive approach to probe the relationship between synapse maturation rates and critical-period plasticity. Consistent with the findings of others (Crair and Malenka, 1995; Harlow et al., 2010), the $\mathrm{A} / \mathrm{N}$ ratio in neurons from WT mice significantly increased over the first postnatal week (Fig. 1B). Strikingly, this ratio did not change in Het animals over the same period (Fig. 1C). The lack of change in the Het ratio appeared to stem

dione (NBQX) plus $10 \mu \mathrm{m}$ bicuculline was perfused to obtain a pure NMDA current. Once a stable NMDA current was obtained, $3 \mu \mathrm{m}$ ifenprodil was applied for 10-15 min until the change in NMDAR-mediated currents stabilized.

For LTP experiments, the perforated patch-clamp configuration was used to eliminate LTP washout. Gramicidin $(200 \mu \mathrm{g} / \mathrm{ml})$ was added to the $\mathrm{KMeSO}_{4}$ internal solution (in $\mathrm{mM}$ ): $130 \mathrm{KMeSO}_{4}, 5 \mathrm{KCl}, 5 \mathrm{NaCl}, 11$ HEPES free acid, $1 \mathrm{MgCl}_{2}$, 4 ATP-Mg, and 0.3 GTP-Na, pH 7.3. Electrodes were front-filled with gramicidin-free internal solution and then backfilled with gramicidin-containing internal solution. After formation of gigaohm seal between the electrode and cell membrane, access resistance was continuously monitored using a hyperpolarizing step. Any cell with an access resistance $>50 \mathrm{M} \Omega$ at any time of the experiment was discarded from analysis. Once stable access was obtained ( $\sim 20-25 \mathrm{~min})$, recordings for LTP experiments commenced. LTP was induced by pairing 100 stimuli at $1 \mathrm{~Hz}$ with postsynaptic depolarization to $0 \mathrm{mV}$.

Data acquisition and storage. All signals were amplified using Multiclamp 700B (Molecular Devices), filtered at $2 \mathrm{kHz}$, digitized (10 kHz), and stored on a personal computer for offline analysis. Analog-to-digital conversion was performed using the Digidata 1440A (Molecular Devices). Data acquisitions and analyses were performed using pClamp 10.2 software (Molecular Devices).

Drugs. In all the experiments, drugs were delivered to the slice preparation via the perfusion system. NBQX, D-2-amino-5-phosphonopentanoate, and bicuculline were all purchased from Tocris Biosciences. All drugs were aliquoted into small quantities in stock concentration and stored at $-20^{\circ} \mathrm{C}$.

Statistics. Statistics were performed using SPSS 20. Data are presented as mean \pm SEM. For LTP experiments, baseline was normalized to initial prestimulus current values. Post hoc Bonferroni's test was performed for appropriate experiments. Student's unpaired $t$ tests or ANOVA was performed to determine the statistical significance as appropriate. Example traces are those recorded for 1-2 min around the time point indicated. from an already increased ratio at the $\mathrm{P} 4$ time point (Fig. $1 B, C$ ). To confirm this notion, we performed a two-way ANOVA that probed for an interaction between genotype and time $\left(F_{(2,35)}=\right.$ $3.367, p<0.05)$. Post hoc tests confirmed this observation, because there was a significant increase in the $\mathrm{A} / \mathrm{N}$ ratio in Het compared with WT animals at P4 that disappeared by P9 (Fig. $1 B, C)$. Importantly, there was no change in the $\mathrm{A} / \mathrm{N}$ ratio in Het mice over time, indicating that these mutants have precociously mature synapses compared with WT mice. NMDAR deactivation kinetics accelerate over approximately the same time course as GluN2A incorporation into TC synapses (Barth and Malenka, 2001). Therefore, calculation of A/N ratios that rely on NMDAR measurements at $+40 \mathrm{mV}$ could be confounded in synapses with altered maturation rates. To confirm that abnormally high $\mathrm{A} / \mathrm{N}$ ratios observed in Het mice in young slices was through a relative change in the peak synaptic current of each receptor subtype, we isolated "pure" AMPAR and NMDAR EPSCs in the TC pathway. Using this alternative method, we also found that Het mice had an elevated $\mathrm{A} / \mathrm{N}$ ratio (Fig. $1 D$ ) at $\mathrm{P} 5$, supporting the idea that excitatory synapses are maturing faster in this TC pathway. We did not find differences between genotypes in evoked NMDAR deactivation kinetics at this age [WT $(n=10), 160 \pm 22 \mathrm{~ms}$; Het $(n=6), 127 \pm 16 \mathrm{~ms} ; p>0.05]$.

We next hypothesized that the precociously high $\mathrm{A} / \mathrm{N}$ ratio observed in Het mice would lead to a restricted duration of critical-period synaptic plasticity. To test this idea, we paired synaptic stimulation of the TC pathway with stellate cell postsynaptic depolarization, a paradigm reported by several groups to elicit decreasing levels of LTP as the first postnatal week progresses 
A

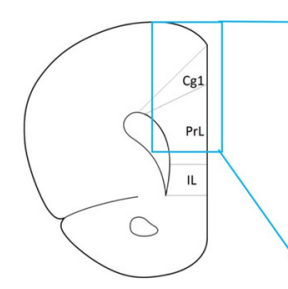

B

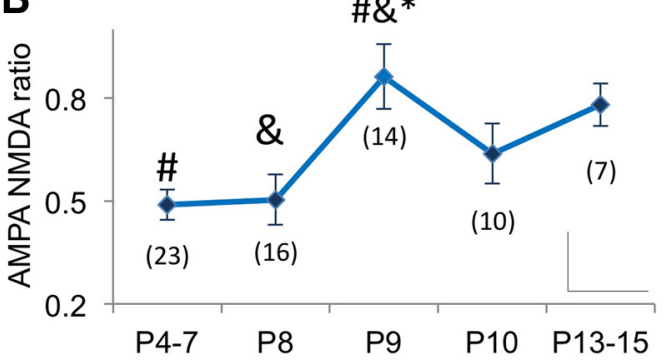

C

高

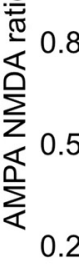

mPFC acute slice

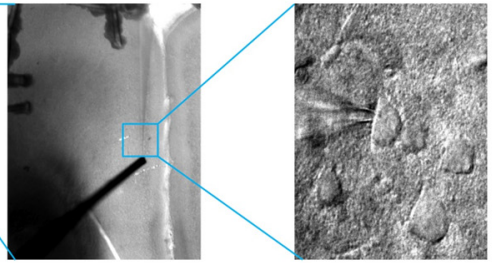

syngap1 WT

\#\&*
PND8

D

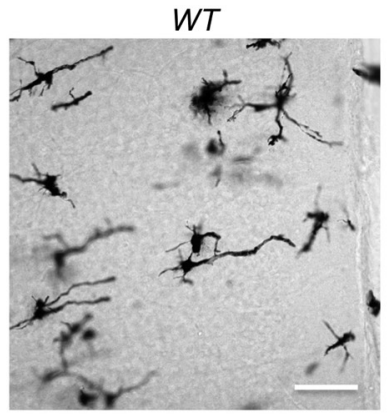

E

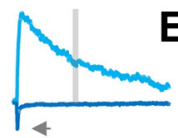

PND9
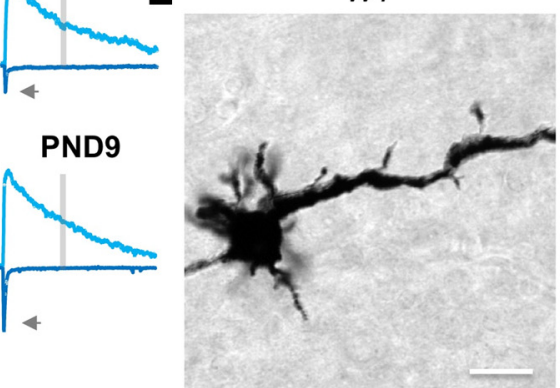

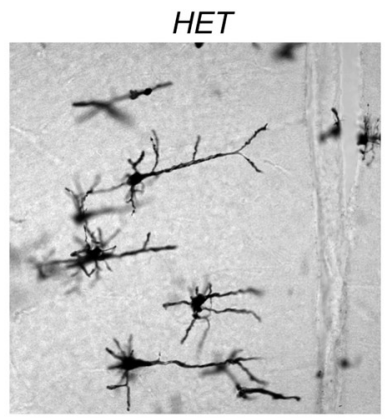

HET

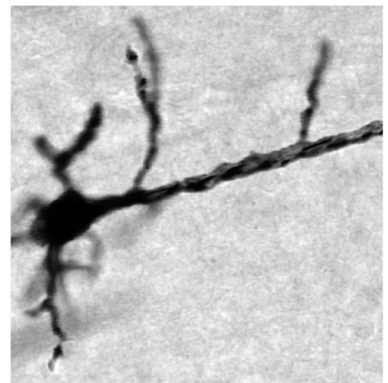

PND8

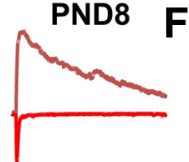

PND9

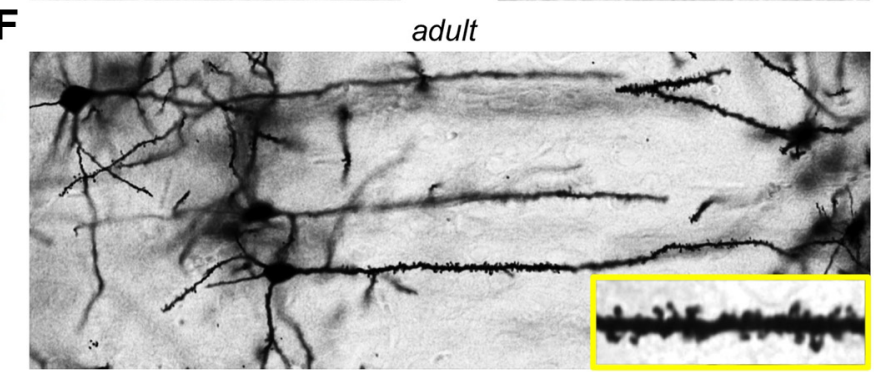

Figure 3. Early excitatory synaptic maturation in $\mathrm{mPFC}$ layer II/III pyramidal neurons. A, A coronal section through the mouse brain illustrating the mPFC. Low-magnification image shows the prelimbic and cingulate cortices, in which recordings were obtained. High-magnification image (rotated $90^{\circ}$ counterclockwise for clarity) shows an example of a layer II/III neuron. Cg1, Cingulate cortex area 1; PrL, prelimbic cortex; L, infralimbic cortex. B, Representative traces and summary data of A/N ratios evoked locally and recorded in layer II/III pyramidal cells in P4-P15 WT. Calibration: $100 \mathrm{pA}, 300 \mathrm{~ms}$. C, Same as $\boldsymbol{B}$ but in Het mice. ${ }^{*} p<0.05$ between genotypes; ${ }^{\#, \&} p<0.05$ within genotypes [2-way ANOVA (data from $\boldsymbol{B}$ and $\boldsymbol{C}$ were included in analysis), Bonferroni's pairwise comparison]. Arrows and dark gray bars indicate the time point at which measurement was obtained from all the experiments. $D$, Golgi-stained mPFC layer II/III neurons from P8 WT or HET mice. Scale bar, $50 \mu \mathrm{m}$. E, Higher magnification of Golgi-stained neurons demonstrating a lack of spines present in both genotypes at this age. Scale bar, $10 \mu \mathrm{m}$. $\boldsymbol{F}$, Adult WT mouse allows a frame of reference for Golgi-stained neurons and dendritic spine labeling. PND, Postnatal day.

(Crair and Malenka, 1995; Harlow et al., 2010). At P5, we were able to robustly induce LTP in all targeted cells in slices derived from WT animals (Fig. $1 E$ ), although, as reported by many others (Crair and Malenka, 1995; Barth and Malenka, 2001; Harlow et al., 2010), LTP disappeared in WT mice by P8 (Fig. 1F). In contrast, LTP was strikingly absent from P5 Het slices (Fig. 1E). The lack of LTP at this early age could reflect a delay in the critical period for LTP. However, this was not the case, because we were also unable to elicit LTP from P8 Het slices (Fig. $1 F$ ). In light of the known role of SynGAP to repress AMPAR surface trafficking (Rumbaugh et al., 2006), the most parsimonious molecular explanation for LTP failure at this synapse would be a precocious unsilencing of developing synapses in this pathway. To test this idea, we performed minimal stimulation experiments in TC slices to directly measure the proportion of silent synapses in each genotype at P5. In line with past studies, we found the WT failure rate to be significantly higher at $-70 \mathrm{mV}$ compared with +40 $\mathrm{mV}$, which indicates the presence of a substantial number of NMDAR-only, or silent, synapses (Fig. $1 G$ ). In contrast, we found an equal number of failures at each holding potential in Het slices, indicating that excitatory synapses in these mutants were prematurely converted from silent to functional. These data argue that early development of excitatory synapses in Het mice, expressed as premature AMPAR accumulation at postsynapses, shortened the duration of this critical window for synaptic plasticity.

In addition to the widespread increase in the $\mathrm{A} / \mathrm{N}$ ratio and synapse unsilencing, other milestones mark the maturation of forebrain excitatory synapses. For instance, NMDARs at forebrain excitatory synapses exhibit a slow developmental switch in subunit composition (Yashiro and Philpot, 2008). In the TC synapse in the barrel cortex, the GluN2A/GluN2B ratio increases over a nearly identical time course as the closure of the LTP and somatosensory map critical periods (Feldman et al., 1999; Barth and Malenka, 2001). Therefore, we hypothesized that GluN2A would accumulate early in Het TC synapses. To test this idea, we evoked NMDAR EPSCs in layer IV stellate cells at two developmental time points and then quantified the level of blockade by the GluN2B-specific antagonist ifenprodil. We observed a significant interaction between age and genotype $\left(F_{(1,18)}=17.37, p<\right.$ 0.001). As reported by others (Barth and Malenka, 2001), we observed an $\sim 70 \%$ blockade of NMDAR EPSCs by this compound at P4-P5 (Fig. 2A). However, the efficacy of this compound was significantly reduced at P8-P9 in WT mice (Fig. 2B), 
reflecting initially low levels of synaptic GluN2A that gradually increases. Strikingly, ifenprodil was much less effective at blocking NMDAR currents in P4-P5 Het mice (Fig. 2A) and was significantly reduced compared with WT mice. The nominal effect of this compound persisted into the P8-P9 time point (Fig. 2B), indicating that GluN2A subunits were incorporated prematurely into Het TC synapses. Interestingly, we did not find differences between genotypes in evoked NMDAR deactivation kinetics at P5 either before or after ifenprodil [before ifenprodil: WT $(n=5)$, $172 \pm 24 \mathrm{~ms} ; \operatorname{Het}(n=5), 143 \pm 24 \mathrm{~ms} ; p>0.05$; after ifenprodil: WT $(n=5), 201 \pm 53 \mathrm{~ms}$; Het $(n=5), 133 \pm 14 \mathrm{~ms} ; p>0.05]$, consistent with the idea that NMDAR subunit composition and speed of deactivation kinetics can be dissociated in these developing synapses (Barth and Malenka, 2001).

We next probed development of glutamatergic connections in layer II/III of the mPFC (Fig. $3 A$ ). We were curious whether alterations in maturation rates at this site were also accelerated, which would support the idea that early maturation of excitation is widespread throughout the cortex in mice with syngap1 truncating mutations. To test for early maturation in the mPFC, we measured daily changes in $\mathrm{A} / \mathrm{N}$ ratios from layer II/III glutamatergic neurons during a time period spanning $\mathrm{P} 4-\mathrm{P} 15(n=131)$. A preliminary analysis showed that there was no difference between genotypes up to P7. As a result, data during this time period were pooled into a single time point (Fig. $3 B$ ). However, differences in the $\mathrm{A} / \mathrm{N}$ ratio were observed during $\mathrm{P} 8$ and $\mathrm{P} 9$, albeit differently between genotypes (Fig. $3 B, C$ ). A two-way ANOVA up to $\mathrm{P} 9$ revealed a significant day $\times$ genotype interaction $\left(F_{(2,89)}=3.940, p<0.05\right)$. The simple main effects were further analyzed by pairwise comparisons using the Bonferroni's adjustment. There was a significant increase in the $\mathrm{A} / \mathrm{N}$ ratio in WT neurons at P9 $(p<0.001)$, which had already occurred in syngap1 Het neurons at P8 $(p<0.05)$. The only other significant difference was a reduction in syngap1 Het neurons compared with WT at P9 $(p<0.05)$, which again suggested early maturation (i.e., reduction happening in WT neurons at P10). The $\mathrm{A} / \mathrm{N}$ ratio stabilized at $\mathrm{P} 10$ onward, and no differences between genotypes were obvious beyond this point. We next Golgi stained (Vetere et al., 2011) WT or Het brains at P8 to determine whether excitatory synapses were located on dendritic spines. Spines were conspicuously lacking in both genotypes at this age (Fig. $3 D, E$ ), although we were able to detect spines in adulthood (Fig. $3 F$ ), indicating that the regulation by syngap 1 of synapse maturation can be dissociated from dendritic spine regulation. Overall, these data demonstrate that development of layer II/III mPFC A/N ratio is accelerated in syngap1 Het, consistent with the idea that SYNGAP1 truncating mutations cause widespread premature development of excitatory synapses in the cortex.

\section{Discussion}

Our original study in the hippocampus reported that excitatory synapse function and dendritic spine morphology demonstrated a precocious and coordinated early maturation that corresponded to disruptions in $\mathrm{E} / \mathrm{I}$ balance and abnormal behavioral adaptations (Clement et al., 2012). Our current study extends this finding in two important ways. First, these data demonstrate that the early synapse maturation phenomenon first observed around the end of the second postnatal week in the hippocampus appears to occur earlier in developing cortical circuits. Interestingly, the period observed to be sensitive to syngap 1 action in cortical synapses (P4-P9) is marked by the conspicuous absence of dendritic spines, structures that develop days later in both of these neurons (Ashby and Isaac, 2011) (Fig. 3D-F). Thus, syngap1 can exert a repressive action over synapses before dendritic spine morphogenesis occurs. Second, because we observed early maturation of excitatory synapse function in two distinct developing cortical synapses, these data argue that SYNGAP1 truncating mutations have a widespread influence on the maturation of excitation in the developing brain. Together, these findings have implications for how intrinsic and/or experience-driven spiking guides early neural organization.

These features of abnormal neural development suggest that SYNGAP1 mutations restrict critical-period efficacy, which in turn disrupts the organization of neural systems that drive cognition and behavior. Indeed, critical periods are a fundamental feature of mammalian brain development (Hensch, 2004), and the opening, closing, and efficacy of these periods rely on an intricate balance of excitation to inhibition (Hensch, 2005; Hensch and Fagiolini, 2005), a process that is clearly disrupted in developing syngap1 Het animals (Clement et al., 2012). Disrupting these periods of heightened brain plasticity can have lasting effects on brain function. Critical-period E/I balance is robustly regulated by the emergence of GABAergic function in developing circuits. However, for GABAergic synapse maturation to initiate critical-period onset and/or duration, earlier neurodevelopmental milestones must be achieved so that a suitable substrate exists (e.g., an organized excitatory network) on which these later events can act (Hensch, 2004). Indeed, the pace of excitatory synapse maturation and the stabilization of these excitatory circuits is one of the earliest neurobiological events in the developing cortex. As a result, widespread early synapse maturation caused by SYNGAP1 mutations likely alters E/I balance during very early periods of development. These disruptions would be expected to alter critical-period efficacy. In support of this idea, our current studies also directly linked early maturation of excitatory synapses to altered windows of plasticity associated with developmental critical periods, providing an additional route to critical-period disruption. Thus, we propose that altered E/I balance caused by precocious development of excitatory synapses combined with restricted windows of synaptic plasticity in nascent circuits act in concert to disrupt neural circuit organization. In this context, transient neurodevelopmental events induced by SYNGAP1 mutations could cause life-long disruptions to cognition and behavior that are difficult to treat in adulthood (Clement et al., 2012).

\section{References}

Agmon A, Connors BW (1991) Thalamocortical responses of mouse somatosensory (barrel) cortex in vitro. Neuroscience 41:365-379. CrossRef Medline

Ashby MC, Isaac JT (2011) Maturation of a recurrent excitatory neocortical circuit by experience-dependent unsilencing of newly formed dendritic spines. Neuron 70:510-521. CrossRef Medline

Barth AL, Malenka RC (2001) NMDAR EPSC kinetics do not regulate the critical period for LTP at thalamocortical synapses. Nat Neurosci 4:235236. CrossRef Medline

Berryer MH, Hamdan FF, Klitten LL, Møller RS, Carmant L, Schwartzentruber J, Patry L, Dobrzeniecka S, Rochefort D, Neugnot-Cerioli M, Lacaille JC, Niu Z, Eng CM, Yang Y, Palardy S, Belhumeur C, Rouleau GA, Tommerup N, Immken L, Beauchamp MH, et al. (2013) Mutations in SYNGAP1 cause intellectual disability, autism, and a specific form of epilepsy by inducing haploinsufficiency. Hum Mutat 34:385-394. CrossRef Medline

Clement JP, Aceti M, Creson TK, Ozkan ED, Shi Y, Reish NJ, Almonte AG, Miller BH, Wiltgen BJ, Miller CA, Xu X, Rumbaugh G (2012) Pathogenic SYNGAP1 mutations impair cognitive development by disrupting maturation of dendritic spine synapses. Cell 151:709-723. CrossRef Medline 
Crair MC, Malenka RC (1995) A critical period for long-term potentiation at thalamocortical synapses. Nature 375:325-328. CrossRef Medline

Feldman DE, Nicoll RA, Malenka RC (1999) Synaptic plasticity at thalamocortical synapses in developing rat somatosensory cortex: LTP, LTD, and silent synapses. J Neurobiol 41:92-101. CrossRef Medline

Fox K, Wong RO (2005) A comparison of experience-dependent plasticity in the visual and somatosensory systems. Neuron 48:465-477. CrossRef Medline

Grant SG (2012) Synaptopathies: diseases of the synaptome. Curr Opin Neurobiol 22:522-529. CrossRef Medline

Guo X, Hamilton PJ, Reish NJ, Sweatt JD, Miller CA, Rumbaugh G (2009) Reduced expression of the NMDA receptor-interacting protein SynGAP causes behavioral abnormalities that model symptoms of Schizophrenia. Neuropsychopharmacology 34:1659-1672. CrossRef Medline

Hamdan FF, Gauthier J, Spiegelman D, Noreau A, Yang Y, Pellerin S, Dobrzeniecka S, Côté M, Perreau-Linck E, Carmant L, D’Anjou G, Fombonne E, Addington AM, Rapoport JL, Delisi LE, Krebs MO, Mouaffak F, Joober R, Mottron L, Drapeau P, Marineau C, Lafrenière RG, Lacaille JC, Rouleau GA, Michaud JL; Synapse to Disease Group (2009) Mutations in SYNGAP1 in autosomal nonsyndromic mental retardation. N Eng J Med [Erratum (2009) 361:1814 (Perreault-Linck, Elizabeth corrected to Perreau-Linck, Elizabeth] 360:599-605. CrossRef Medline

Hamdan FF, Daoud H, Piton A, Gauthier J, Dobrzeniecka S, Krebs MO, Joober R, Lacaille JC, Nadeau A, Milunsky JM, Wang Z, Carmant L, Mottron L, Beauchamp MH, Rouleau GA, Michaud JL (2011) De novo SYNGAP1 mutations in nonsyndromic intellectual disability and autism. Biol Psychiatry 69:898-901. CrossRef Medline

Harlow EG, Till SM, Russell TA, Wijetunge LS, Kind P, Contractor A (2010) Critical period plasticity is disrupted in the barrel cortex of FMR1 knockout mice. Neuron 65:385-398. CrossRef Medline

Hensch TK (2004) Critical period regulation. Annu Rev Neurosci 27:549579. CrossRef Medline

Hensch TK (2005) Critical period mechanisms in developing visual cortex. Curr Top Dev Biol 69:215-237. CrossRef Medline
Hensch TK, Fagiolini M (2005) Excitatory-inhibitory balance and critical period plasticity in developing visual cortex. Prog Brain Res 147:115-124. CrossRef Medline

Isaac JT, Crair MC, Nicoll RA, Malenka RC (1997) Silent synapses during development of thalamocortical inputs. Neuron 18:269-280. CrossRef Medline

Kim JH, Liao D, Lau LF, Huganir RL (1998) SynGAP: a synaptic RasGAP that associates with the PSD-95/SAP90 protein family. Neuron 20:683691. CrossRef Medline

Kim JH, Lee HK, Takamiya K, Huganir RL (2003) The role of synaptic GTPase-activating protein in neuronal development and synaptic plasticity. J Neurosci 23:1119-1124. Medline

LeBlanc JJ, Fagiolini M (2011) Autism: a "critical period" disorder? Neural Plast 2011:921680. CrossRef Medline

McMahon AC, Barnett MW, O’Leary TS, Stoney PN, Collins MO, Papadia S, Choudhary JS, Komiyama NH, Grant SG, Hardingham GE, Wyllie DJ, Kind PC (2012) SynGAP isoforms exert opposing effects on synaptic strength. Nat Commun 3:900. CrossRef Medline

Pinto D, Pagnamenta AT, Klei L, Anney R, Merico D, Regan R, Conroy J, Magalhaes TR, Correia C, Abrahams BS, Almeida J, Bacchelli E, Bader GD, Bailey AJ, Baird G, Battaglia A, Berney T, Bolshakova N, Bölte S, Bolton PF, et al. (2010) Functional impact of global rare copy number variation in autism spectrum disorders. Nature 466:368-372. CrossRef Medline

Rumbaugh G, Adams JP, Kim JH, Huganir RL (2006) SynGAP regulates synaptic strength and mitogen-activated protein kinases in cultured neurons. Proc Natl Acad Sci U S A 103:4344-4351. CrossRef Medline

Vetere G, Restivo L, Novembre G, Aceti M, Lumaca M, Ammassari-Teule M (2011) Extinction partially reverts structural changes associated with remote fear memory. Learn Mem 18:554-557. CrossRef Medline

Yashiro K, Philpot BD (2008) Regulation of NMDA receptor subunit expression and its implications for LTD, LTP, and metaplasticity. Neuropharmacology 55:1081-1094. CrossRef Medline 